\title{
Avaliação do comportamento de quinze cultivares de cana-de-açucar na Região Sul do Tocantins
}

\author{
Aristoteles Capone ${ }^{1 *}$, Jandislau José Lui ${ }^{1}$, Thiago Romualdo da Silva ${ }^{1}$, Marilene \\ Alves Ramos Dias ${ }^{1}$ e Aurélio Vaz de Melo ${ }^{1}$
}

${ }^{I}$ Departamento de Agronomia; Universidade Federal do Tocantins; 77402-970; Gurupi - TO - Brasil.

\begin{abstract}
The cultivation of sugar cane (Saccharum spp.) is featured in the agricultural scenario of Brazil, can be attributed to its high adaptability to different environments. The objective of this study was to evaluate the behavior of fifteen cultivars of sugar cane in conditions of climate and soil of southern Tocantins, in conditions of cane the first year (2005/2006) and the second year (2006/2007). The experimental design was of randomized blocks, with fifteen treatments (cultivars) and three repetitions. The cultivars utilized were: RB84-5210, RB85-5113, RB85-5453, RB86-7515, RB83-5486, RB56-5230, RB85-5536, RB928064, SP80-1842, SP85-3877, SP81-3250, SP80-1816, SP87-365, SP86-155, IAC86-2480. The characteristics evaluated were: total height cane (ATC, in $\mathrm{m}$ ); soluble solids (BRIX, in ${ }^{\circ}$ Brix); number of cane per hectare $(\mathrm{NCH}$, in $\mathrm{NC} / \mathrm{ha})$ and productivity $\left(P R O D\right.$, in $\left.\mathrm{kg} \mathrm{ha}^{-1}\right)$. The experimental data were analyzed individually and, after, joint analysis for some characteristics, for comparison between groups of means test was utilized grouping Scott and Knott (1974) the 5\% significance. The characteristics ATC and NC/ha correlates directly with productivity. The cultivars RB56-5230, SP80-1816, RB85-155 and SP86-5536 were the most productive. The cultivars SP80-1816 and RB85-5536 obtained the best results in quantitative and qualitative parameters.
\end{abstract}

Key words: Saccharum spp, environments, productivity, quantitative and qualitative

\section{INTRODUÇÃO}

A cana-de-açúcar tem como origem a Nova Guiné. Os persas parecem ter sido os primeiros a desenvolverem as técnicas de produção de açúcar na forma cristalizada, tal como atualmente se conhece. (Delgado e Cesar, 1977). Em 1973, iniciou-se grave crise energética quando os países da OPEP começaram a aumentar o preço do barril de petróleo. Com isso, o Brasil iniciou busca por fontes alternativas de energia, criando o Programa Nacional do Álcool em 1975 (Bernardes e Câmara, 2001).

Segundo Barbosa et al., (2000), nas três últimas décadas, foi marcante a contribuição do melhoramento genético no desenvolvimento do

setor canavieiro no Brasil, com ganhos acentuados de produtividade e qualidade. Esses ganhos proporcionaram mais de $30 \%$ de aumento na média de produtividade da cana-de-açúcar.
O Brasil é um dos países com maiores potenciais de produção de cana de açúcar e seus derivados. Visto que, possui condições edafoclimáticas favoráveis ao desenvolvimento da cultura; uma vez que se trata de uma planta $\mathrm{C}_{4}$ com altas taxas fotossintéticas e alta eficiência de conversão radiante em energia química (Bernardes, 1987). Além de possuir áreas que podem ser exploradas com a cultura. No país a cultura é cultivada em vários tipos de solos que estão sob influência de diferentes climas, o que resulta em vários tipos de ambientes de produção desta cultura (Dias et al., 1997).

Ambientes estes que podem interferir na produção e maturação da cultura, tendo como principais fatores a interação edafoclimática, manejo da cultura e a cultivar escolhida (Cesar et al., 1987). Como citados por Delgado and Cesar, (1977) solos argilosos com maior pacidade de retenção hídrica podem

Author for correspondence: aristotelescapone@hotmail.com 
retardar a maturação da cana, por outro lado, em solos arenosos, mais permeáveis, a maturação pode ser antecipada e acelerada. Com isso, busca-se a utilização de cultivares adequados e práticas culturais modernas a cada tipo de ambiente imposto sobre a cultura, possibilitando assim, aumentos consideráveis de produtividade.

No que se refere aos fatores climáticos à produção da cana-de-açúcar, a temperatura é, provavelmente, o de maior importância. A temperatura basal para a cana-de-açúcar está em torno de $20^{\circ} \mathrm{C}$. A temperatura ótima situa-se entre 22 a $30^{\circ} \mathrm{C}$, sendo que nestas condições a cultura apresenta seu máximo crescimento. Acima de $38{ }^{\circ} \mathrm{C}$ não há crescimento (Magalhães, 1987).

A introdução de cultivares é a forma mais utilizada para avaliar as interações genótipo $\mathrm{x}$ ambiente. Possibilitando conhecer as diferenças funcionais e estruturais entre cultivares de mesma espécie auxiliando na seleção dos mais adaptados (Kang and Miller, 1984).

O Tocantins é considerado como a nova fronteira agrícola, disponibilizando áreas, clima e hidrografia favoráveis a produção de cana-de-açúcar. Com isso, iniciou pesquisas na buscas de informações de plantio da denominada cana-planta e soqueiras que podem ser denominadas de primeira soca, segunda soca, etc. Essas têm grande importância econômica, pois delas é que se retira maior retorno monetário nessa cultura (Matsuoka, 1996).

Objetivou-se com este estudo avaliar o comportamento de quinze cultivares de cana-de-açúcar nas condições de clima e solo da região sul do Tocantins, nas condições de cana de primeiro ano (2005/2006) e de segundo ano (2006/2007).

\section{MATERIAL E MÉTODOS}

O experimento foi conduzido nos anos agrícola 2005/2006, na Universidade Federal do Tocantins, Campus Universitário de Gurupi, Estado do Tocantins. Localizada a $11^{\circ} 43^{\prime}$ de latitude Sul e $49^{\circ} 04^{\prime}$ de longitude Oeste e altitude de $280 \mathrm{~m}$. A temperatura média anual varia de $22{ }^{\circ} \mathrm{C}$ a $32{ }^{\circ} \mathrm{C}$, com umidade relativa média do ar em torno de $76 \%$, precipitação anual média de $1.400 \mathrm{~mm}$ e solo do tipo Latossolo Vermelho Amarelo Distrófico (EMBRAPA, 1999). Os tratamentos foram composto por quinze cultivares de cana-deaçúcar, sendo eles: RB84-5210, RB855113, RB85-5453, RB86-7515, RB835486, RB56-5230, RB85-5536, RB928064 ,

SP80-1842, SP85-3877, SP81-3250, SP801816, SP87-365, SP86-155, IAC86-2480.

As análises física do solo foram realizadas no laboratório de solos da Universidade Federal do Tocantins. As principais características foram: 0 a $20 \mathrm{~cm}$; areia = $63,1 \%$; silte $=9,8 \%$; argila $=27,2 \%$ e 0 a $40 \mathrm{~cm} ;=61,4 \%$; silte $=9,8 \%$; argila $=$ $28,8 \%$.

O clima, segundo o método de Thornthwaite, é do tipo Aw, (clima úmido com moderada deficiência hídrica) (SEPLAN, 2003).

A área de plantio foi preparada com arado de discos, com profundidade de 20 a 30 centímetros. Foi efetuada a calagem com duas toneladas por hectare, utilizando-se calcário dolomítico com PRNT de $95 \%$. Após a calagem realizou-se uma aragem e duas gradagem, utilizando a grade niveladora. $\mathrm{O}$ sulco foi realizado a 1,5 metros entre linhas, com profundidade de 40 a 50 centímetros.

A adubação de plantio foi de $700 \mathrm{~kg} \mathrm{ha}^{-1}$ com a fórmula 04-30-16, aplicada no sulco, anterior a distribuição das canas planta. O plantio foi realizado em 28/08/2005, sobrepondo-se três canas de forma contínua, transpassadas em 40 centímetros pé com ponta, preconizando 24 a 30 gemas por metro linear. Sobre as canas planta foi pulverizado o inseticida, cupinicida do grupo químico fenil-pirazóis, diluído em água, na dosagem de uma grama por 0,6 litros de água.

O sistema de irrigação foi por aspersão convencional, com aplicação média semanal de $40 \mathrm{~mm}$ (três vezes por semana). $\mathrm{O}$ único trato cultural empregado foi capinas manuais, efetuadas à medida que se fizeram necessários. A colheita foi efetuada de forma manual em 26/08/06, encerrando o ciclo de plantio.

Os tratamentos de soqueira iniciaram logo após o corte do plantio. A adubação da soqueira foi de $700 \mathrm{~kg} \mathrm{ha}^{-1}$ na formulação 5-25-15 + Zn. A irrigação de arranque foi de $240 \mathrm{~mm}$, dividida em oito semanas, com turno de rega de três vezes por semana, o único trato cultural foi uma capina. A 
colheita foi efetuada de forma manual em 28/08/07, encerrando o ciclo da soca.

$\mathrm{O}$ delineamento experimental utilizado foi de blocos casualizados, com 15 tratamentos (cultivares), e três repetições. Cada parcela foi constituída por 4 linhas de $10,0 \mathrm{~m}$ de comprimento, e espaçadas de $1,50 \mathrm{~m}$ entre linhas, total de $60 \mathrm{~m}^{2}$. Somente as duas linhas centrais foram consideradas como parcelas úteis nas avaliações.

As características avaliadas foram: altura total da cana: do solo até o final da bainha (ATC, em m); leitura de BRIX (teor de sólidos solúveis): no sétimo colmo descente com refractômetro manual (BRIX, em ${ }^{\circ}$ Brix); número de cana por hectare: estimativa a partir do número de canas colhidas nas parcelas úteis $(\mathrm{NCH}$, em $\mathrm{NC} / \mathrm{ha}$ ) e produtividade de cana-de-açúcar: estimativa do peso de todas as canas das parcelas úteis sem as ponteiras (PROD, em $\mathrm{kg} \mathrm{ha}^{-1}$ ).

Os dados meteorológicos de temperatura, umidade relativa do ar e precipitação pluvial durante a execução do experimento encontram-se na Figura1.

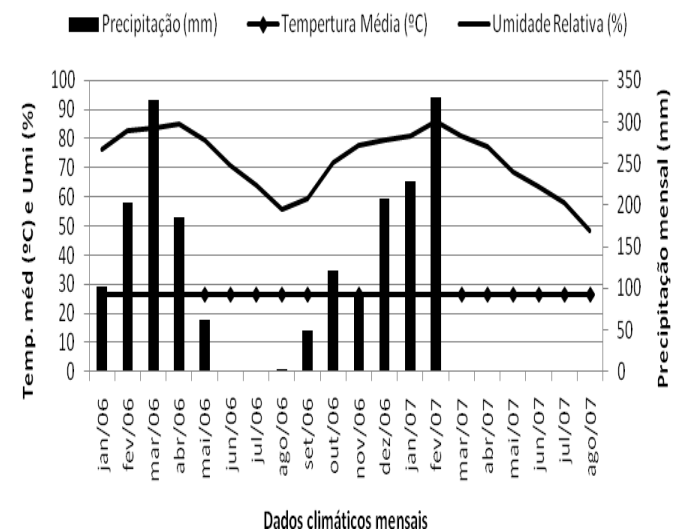

Figura 1- Valores médios mensais de temperaturas $\left({ }^{\circ} \mathrm{C}\right)$, umidade relativa do ar $(\%)$ e total mensal de precipitação pluvial (mm) ocorridas durante o período de janeiro de 2006 a agosto de 2007, Gurupi, TO.

Os dados experimentais foram submetidos à análise individual e, posteriormente, análise conjunta para algumas características. Visto que, o maior quadrado médio do resíduo dividido pelo menor foi inferior a sete, apresentando assim, homogeneidade de variância e sendo possível realizar a análise conjunta (Tabela 1). Nas comparações entre grupos de médias foi utilizado o teste de agrupamento de Scott and Knott (1974) a 5 $\%$ de significância, obtido a partir do aplicativo computacional em genética e estatística - GENES (Cruz, 2001).

\section{RESULTADOS E DISCUSSÃO}

As características ATC e BRIX apresentaram coeficientes de variação abaixo de 10, enquanto $\mathrm{NCH}$ e $\mathrm{TCH}$ apresentaram valores acima de 20 (Tabela1). O coeficiente de variação genético teve o mesmo comportamento do coeficiente de variação experimental. Também se avaliou o coeficiente de determinação, cujo valor é obtido pela divisão do coeficiente de variação genética pelo coeficiente de variação ambiental. De acordo com os resultados da análise de variância conjunta observou-se que $o$ parâmetro ATC é influenciado pelo potencial genético dos cultivares (valor acima de um), enquanto que as características BRIX, NCH e PROD são influenciadas pelo ambiente (valores abaixo de um).

A altura das plantas de cana-de-açúcar, segundo Machado et al (1982), se processa em três fases: a fase inicial de crescimento lento, a fase de crescimento rápido e a fase final de crescimento lento.

A característica altura de cana-de-açúcar (Tabela 2), no plantio teve formação de três grupos, ficando no grupo superior os seguintes cultivares SP80-1816, SP853877, RB56-5230, SP86-155, RB85-5536, SP81-3250, RB92-8064, RB86-7515 e SP80-1842, com suas alturas variando de 4,17 a 4,70 m. Para soca teve-se a formação de dois grupos, ficando inseridos no grupo superior os seguintes cultivares SP80-1816, SP85-3877, RB56-5230, RB85-5536, SP81-3250, RB86-7515, RB85-5453, SP80-1842, e SP86-155, com suas alturas variando de 4,97 a 5,23 m.

$\mathrm{Na}$ média (Tabela 2), observou-se a formação de três grupos, ficando no grupo dos cultivares com maior altura de planta os seguintes cultivares SP80-1816, SP853877, RB56-5230, RB85-5536, SP81-3250, RB86-7515, SP86-155 e SP80-1842, com altura média variando de 4,58 a 4,96 m. Isso pode ser pela sua composição genética de entre nós curtos. 
Tabela 1. Análise de Variância conjunta das características ATC - altura total da cana em (m), BRIX - brix em ( ${ }^{\circ}$ Brix), NCH - número de cana por hectare em $\left(\mathrm{nc} \mathrm{ha}^{-1}\right)$ e PROD - quilos de cana-de-açúcar por hectare em $\left(\mathrm{kg} \mathrm{ha}^{-1}\right)$, de quinze cultivares de cana-de-açúcar, plantio (safra 2005/2006) e primeira soca (safra 2006/2007), Gurupi-TO.

\begin{tabular}{cccccc}
\hline \multirow{2}{*}{ F.V. } & \multirow{2}{*}{ GL } & \multicolumn{4}{c}{ Quadrado Médio } \\
\cline { 3 - 6 } & 4 & ATC & BRIX & NCH & TCH \\
\hline B/A & 0,20 & 2,35 & 270226925 & 938451435 \\
CULTI & 14 & 0,66 & 8,53 & 18235074621 & 4321344974 \\
AMB & 1 & 13,85 & 130,80 & 3526041454 & 557509618 \\
CUL X AMB & 14 & 0,09 & 2,91 & 275900950 & 292153990 \\
RESIDUO & 56 & 0,07 & 1,41 & 294972466 & 759385389 \\
\hline MÉDIA & & 4,53 & 21,82 & 60793 & 89960 \\
\hline CV & & 5,88 & 5,44 & 28,2 & 30,6 \\
\hline CVg & & 6,80 & 4,44 & 26,4 & 28,8 \\
\hline CVg/CVe & & 1,16 & 0,82 & 0,94 & 0,94 \\
\hline
\end{tabular}

*,** - Significativo a 5 e $1 \%$ de probabilidade, respectivamente, pelo teste $\mathrm{F} .{ }^{\text {ns }}$ - Não significativo.

Tabela 2. Médias estimadas da altura total da cana (ATC- m), de quinze cultivares de cana-deaçúcar, plantio (safra 2005/2006) e primeira soca (safra 2006/2007), Gurupi-TO.

\begin{tabular}{cccc}
\hline Cultivares & ATC Plantio & ATC Soca & Média \\
\hline RB84-5210 & $4,00 \mathrm{Bb}$ & $4,77 \mathrm{Ab}$ & $4,38 \mathrm{~b}$ \\
RB85-5113 & $3,77 \mathrm{Bb}$ & $4,57 \mathrm{Ab}$ & $4,16 \mathrm{~b}$ \\
RB85-5453 & $3,80 \mathrm{Bb}$ & $5,17 \mathrm{Aa}$ & $4,48 \mathrm{~b}$ \\
RB86-7515 & $4,27 \mathrm{Ba}$ & $5,17 \mathrm{Aa}$ & $4,71 \mathrm{a}$ \\
RB83-5486 & $3,83 \mathrm{Bb}$ & $4,83 \mathrm{Ab}$ & $4,33 \mathrm{~b}$ \\
RB56-5230 & $4,47 \mathrm{Ba}$ & $5,17 \mathrm{Aa}$ & $4,81 \mathrm{a}$ \\
RB85-5536 & $4,37 \mathrm{Ba}$ & $5,17 \mathrm{Aa}$ & $4,76 \mathrm{a}$ \\
RB92-8064 & $4,30 \mathrm{Aa}$ & $4,60 \mathrm{Ab}$ & $4,45 \mathrm{~b}$ \\
SP80-1842 & $4,17 \mathrm{Ba}$ & $5,00 \mathrm{Aa}$ & $4,58 \mathrm{a}$ \\
SP85-3877 & $4,50 \mathrm{Ba}$ & $5,20 \mathrm{Aa}$ & $4,85 \mathrm{a}$ \\
SP81-3250 & $4,33 \mathrm{Ba}$ & $5,17 \mathrm{Aa}$ & $4,75 \mathrm{a}$ \\
SP80-1816 & $4,70 \mathrm{Ba}$ & $5,23 \mathrm{Aa}$ & $4,96 \mathrm{a}$ \\
SP87-365 & $3,93 \mathrm{Bb}$ & $4,57 \mathrm{Ab}$ & $4,25 \mathrm{~b}$ \\
SP86-155 & $4,40 \mathrm{Ba}$ & $4,97 \mathrm{Aa}$ & $4,68 \mathrm{a}$ \\
IAC86-2480 & $3,17 \mathrm{Bc}$ & $4,20 \mathrm{Ab}$ & $3,68 \mathrm{c}$ \\
\hline Média & $4,13 \mathrm{~B}$ & $4,92 \mathrm{~A}$ & \\
\hline
\end{tabular}

Grupos de médias seguidas por uma mesma letra maiúscula na linha e minúscula na coluna, não diferem significativamente pelo teste de agrupamento de Scott and Knott a 5\% de significância.

De acordo com Shigaki (2003), avaliando variedades de cana-de-açúcar sobre déficit hídrico verificou que a disponibilidade de água no solo é o principal fator responsável pela maior elongação dos entre nós, o que explica os altos valores obtidos na presente pesquisa, que teve irrigação inicial de 240 $\mathrm{mm}$ distribuído em oito semanas para o plantio e soca. O que também pode explicar o melhor resultado obtido pela soca. Visto que, ao lançar os perfilhos tem-se maior aproveitamento de água devido o sistema radicular já está estabelecido. Com isso a soca tem maior conversão fotossintética, resultando num alongamento de entre nós e maior altura em relação ao plantio.

A característica BRIX (sólidos solúveis totais) (Tabela 3), medida em ${ }^{\circ}$ Brix obteve a formação de dois grupos de média no plantio, ficando no grupo superior os seguintes cultivares RB85-5453, RB835486, RB84-5210, RB85-5113, SP80-1842, SP80-1816, RB85-5536, RB86-7515 e SP81-3250. Os BRIX desses cultivares 
variaram de 23,33 a $24,17{ }^{\circ}$ Brix. Já no cultivo da soca obteve-se a formação de três grupos, ficando inseridos no grupo de BRIX superiores os cultivares RB85-5453, RB86-7515, RB84-5210, e SP80-1842, com seus BRIX variando de 22,20 a $23,33^{\circ}$ Brix. Para Fernandes (1985), o estágio de maturação da cana com relação ao ${ }^{\circ}$ Brix, o valor ideal para considerá-la madura é de no mínimo $18,0 \%$ durante todo o decorrer da safra, desta forma todos ao cultivares no plantio e soca foram colhidos maduros, pois obtiveram ${ }^{\circ}$ Brix acima de $18,0 \%$.

$\mathrm{Na}$ média, independentemente da colheita de plantio ou soca (Tabela 3), obteve-se a formação de dois grupos, os cultivares inseridos no grupo dos superiores foram RB85-5453, RB86-7515, RB84-5210, SP80-1842, RB83-5486, RB85-5536, SP81-3250 e SP80-1816, com seus BRIX médios variando de 22,08 a $23,75^{\circ}$ Brix.

De acordo com Azevedo (1981), A diminuição da temperatura tem efeito direto na absorção de nutrientes, a qual, se reduzida, diminui o desenvolvimento vegetativo e a maior parte dos açúcares produzidos é armazenada. No Tocantins como visto na Figura 01, não há queda de temperatura.

Com isso, o que faz a cana-de-açúcar acumular sacarose é o stress provocado pela diminuição da umidade do solo, que reduz do teor de água nos tecidos da planta, e a desidratação força a conversão de açúcares redutores em sacarose, outro fator ligado a desidratação são solos arenosos, que são mais permeáveis, fazendo que a maturação seja antecipada e acelerada (Delgado and Cesar,1977; Azevedo, 1981; Cesar et al., 1987).

A pesquisa foi implantada sobre solo de $63,1 \%$ (0 a $20 \mathrm{~cm})$ e $61,4 \%(20$ a $40 \mathrm{~cm}$ ) de areia, desta forma a cana-de-açúcar iniciou sua maturação logo após o fim do período chuvoso, que no plantio encerrou em maio de 2006 e na soca encerrou em fevereiro de 2007 (Figura 01). Os melhores resultados obtidos na média pelo plantio podem ser explicados por um período mais longo de chuvas, resultando num maior acumulo de açucares.

Tabela 3. Médias estimadas do BRIX em ( ${ }^{\circ}$ Brix), de quinze cultivares de cana-de-açucar, plantio (safra 2005/2006) e primeira soca (safra 2006/2007), Gurupi-TO.

\begin{tabular}{crrr}
\hline Cultivares & ${ }^{\mathbf{0}}$ Brix Plantio & ${ }^{\mathbf{0}}$ Brix Soca & Média \\
\hline RB84-5210 & $24,00 \mathrm{Aa}$ & $22,37 \mathrm{Aa}$ & $23,18 \mathrm{a}$ \\
RB85-5113 & $24,00 \mathrm{Aa}$ & $18,03 \mathrm{Bc}$ & $21,02 \mathrm{~b}$ \\
RB85-5453 & $24,17 \mathrm{Aa}$ & $23,33 \mathrm{Aa}$ & $23,75 \mathrm{a}$ \\
RB86-7515 & $23,50 \mathrm{Aa}$ & $22,90 \mathrm{Aa}$ & $23,20 \mathrm{a}$ \\
RB83-5486 & $24,17 \mathrm{Aa}$ & $20,90 \mathrm{Bb}$ & $22,53 \mathrm{a}$ \\
RB56-5230 & $22,17 \mathrm{Ab}$ & $18,60 \mathrm{Bc}$ & $20,38 \mathrm{~b}$ \\
RB85-5536 & $23,67 \mathrm{Aa}$ & $20,90 \mathrm{Bb}$ & $22,28 \mathrm{a}$ \\
RB92-8064 & $21,83 \mathrm{Ab}$ & $19,63 \mathrm{Bc}$ & $20,73 \mathrm{~b}$ \\
SP80-1842 & $24,00 \mathrm{Aa}$ & $22,20 \mathrm{Aa}$ & $23,10 \mathrm{a}$ \\
SP85-3877 & $22,50 \mathrm{Ab}$ & $19,06 \mathrm{Bc}$ & $20,78 \mathrm{~b}$ \\
SP81-3250 & $23,33 \mathrm{Aa}$ & $21,00 \mathrm{Bb}$ & $22,17 \mathrm{a}$ \\
SP80-1816 & $23,83 \mathrm{Aa}$ & $20,33 \mathrm{Bc}$ & $22,08 \mathrm{a}$ \\
SP87-365 & $21,00 \mathrm{Ab}$ & $20,00 \mathrm{Ac}$ & $20,50 \mathrm{~b}$ \\
SP86-155 & $21,17 \mathrm{Ab}$ & $20,73 \mathrm{Ab}$ & $21,45 \mathrm{~b}$ \\
IAC86-2480 & $21,00 \mathrm{Ab}$ & $19,17 \mathrm{Ac}$ & $20,08 \mathrm{~b}$ \\
\hline Média & $23,02 \mathrm{~A}$ & $20,61 \mathrm{~B}$ & \\
\hline
\end{tabular}

Grupos de médias seguidas por uma mesma letra maiúscula na linha e minúscula na coluna, não diferem significativamente pelo teste de agrupamento de Scott and Knott a 5\% de significância.

A característica número de cana por hectare (Tabela 4), observa-se que no plantio teve a formação de dois grupos de médias de número de cana por hectare, sendo o grupo com maior número de plantas composto pelos cultivares RB56-5230, RB85-5536, SP80-1816, SP86-155, e SP81-3250, com 
número de cana por hectare variando entre 61555 e 84666. Para a soca também houve a formação de dois grupos, sendo agrupados como superiores os seguintes cultivares RB56-5230, IAC86-2480, SP86155, e SP80-1816, com número de cana por hectare variando entre 86666 e 110888.

$\mathrm{Na}$ média (Tabela 4) os cultivares agrupados como superiores foram RB565230, SP86-155, IAC86-2480, SP80-1816, RB85-5536 e SP81-3250 com número de cana por hectare médio variando entre 65777 e 97777 . Não houve significância, mas verificou-se superioridade de 18,66\% de da soca para o plantio.

O índice de perfilhamento da cana-deaçúcar é uma característica varietal e a capacidade de perfilhamento e a sobrevivência dos perfilhos são aspectos importantes, pois são características que apresentam grande correlação com a produção (James, 1971 e Mariotti, 1971). Outro fator importante para o perfilhamento é a intensidade luminosa que, em condições de maiores intensidades a cultura tende a perfilhar mais (Bezuidenhout, 2003). Para Silva Júnior (2001), a luz não influenciou na germinação, mas o perfilhamento é favorecido pela alta intensidade luminosa e o número de brotos vivos depende da quantidade de luz incidente e, de acordo como Casagrande (1991) o perfilhamento também aumenta com o aumento da temperatura até o máximo ao redor de $30^{\circ} \mathrm{C}$. Desta forma a cultura da cana-de-açúcar no Estado do Tocantins tende a ter número de perfilhamento alto devido a baixa latitude $\left(11^{\circ} 43^{\prime}\right)$, que proporciona ao estado uma alta intensidade luminosa. Como citado acima o perfilhamento é uma característica varietal, os cultivares RB56-5230, SP801816 e SP86-155 confirmam esta citação, pois foram os que obtiveram maior número de perfilho no plantio e na soca, outro exemplo é o do cultivar RB83-5486, que obteve o menor número de perfilhos no plantio e soca.

Tabela 4. Médias estimadas do número de cana por hectare em $(\mathrm{NC} / \mathrm{ha})$, de quinze cultivares de cana-de-açúcar, plantio (safra 2005/2006) e primeira soca (safra 2006/2007), Gurupi-TO.

\begin{tabular}{cccc}
\hline Cultivares & NCH Plantio & NCH Soca & Média \\
\hline RB84-5210 & $51777 \mathrm{Ab}$ & $52222 \mathrm{Ab}$ & $51999 \mathrm{~b}$ \\
RB85-5113 & $46222 \mathrm{Ab}$ & $49777 \mathrm{Ab}$ & $47999 \mathrm{~b}$ \\
RB85-5453 & $46666 \mathrm{Ab}$ & $49999 \mathrm{Ab}$ & $48333 \mathrm{~b}$ \\
RB86-7515 & $42888 \mathrm{Ab}$ & $52666 \mathrm{Ab}$ & $47777 \mathrm{~b}$ \\
RB83-5486 & $33333 \mathrm{Ab}$ & $33555 \mathrm{Ab}$ & $33444 \mathrm{~b}$ \\
RB56-5230 & $84666 \mathrm{Aa}$ & $110888 \mathrm{Aa}$ & $97777 \mathrm{a}$ \\
RB85-5536 & $74222 \mathrm{Aa}$ & $69999 \mathrm{Ab}$ & $72111 \mathrm{a}$ \\
RB92-8064 & $43333 \mathrm{Ab}$ & $53333 \mathrm{Ab}$ & $48333 \mathrm{~b}$ \\
SP80-1842 & $47999 \mathrm{Ab}$ & $59999 \mathrm{Ab}$ & $53999 \mathrm{~b}$ \\
SP85-3877 & $47111 \mathrm{Ab}$ & $66888 \mathrm{Ab}$ & $56999 \mathrm{~b}$ \\
SP81-3250 & $61555 \mathrm{Aa}$ & $69999 \mathrm{Ab}$ & $65777 \mathrm{a}$ \\
SP80-1816 & $68888 \mathrm{Aa}$ & $86666 \mathrm{Aa}$ & $77777 \mathrm{a}$ \\
SP87-365 & $47555 \mathrm{Ab}$ & $49999 \mathrm{Ab}$ & $48777 \mathrm{~b}$ \\
SP86-155 & $64222 \mathrm{Ba}$ & $99333 \mathrm{Aa}$ & $81777 \mathrm{a}$ \\
IAC86-2480 & $57555 \mathrm{Bb}$ & $100444 \mathrm{Aa}$ & $78999 \mathrm{a}$ \\
\hline Média & $54533 \mathrm{~A}$ & $67051 \mathrm{~A}$ & \\
\hline
\end{tabular}

Grupo de médias seguidas por uma mesma letra maiúscula na linha e minúscula na coluna, não diferem significativamente pelo teste de agrupamento de Scott and Knott a 5\% de significância.

A característica produtividade de cana (Tabela 5), obteve no plantio a formação de dois grupos, sendo composto o grupo superior pelos seguintes cultivares SP801816, RB56-5230, RB85-5536, SP86-155 e SP81-3250, com a produtividade variando entre 98844 e $136289 \mathrm{~kg} / \mathrm{ha}$. Para a soca também houve a formação de dois grupos, ficando inseridos no grupo dos superiores os seguintes cultivares RB56-5230, SP801816, SP86-155, RB85-5536 e IAC86- 
2480, com a produtividade variando entre 104444 e $158222 \mathrm{~kg} / \mathrm{ha}$.

Na média (Tabela 5), obteve a formação de dois grupos, ficando inseridos no grupo dos superiores os seguintes cultivares RB565230, SP80-1816, SP86-155 e RB85-5536, com a produtividade média variando entre 112988 e $146233 \mathrm{~kg} / \mathrm{ha}$.

Segundo Alfonsi et al (1987), os fatores ambientais que afetam de maneira marcante a produção de cana-de-açúcar são: temperatura, disponibilidade de água, de nutrientes e intensidade luminosa e de acordo com Scarpari (2002), o clima, a variedade, o tipo de solo, o estágio de corte, a data do plantio, entre outros, são fatores que influenciam a produtividade agrícola da cana-de-açúcar.

Desta forma pode-se dizer que o Estado do Tocantins é um estado promissor na produção de cana-de-açúcar, têm altas temperaturas e intensidade luminosa, um período chuvoso bem definido (Figura 1), que propicia um ótimo planejamento de plantio e colheita, ficando apenas o tipo de solo que no geral é arenoso, com isso precisa-se de uma irrigação de arranque bemdistribuída, mas pode-se afirmar que os cultivares RB56-5230, SP80-1816, SP86155 e RB85-5536 se adaptaram bem as condições do estado, atingindo produtividades acima de 110 toneladas.

Tabela 5. Médias estimadas da Produtividade de cana-de-açúcar em $(\mathrm{kg} / \mathrm{ha})$, de quinze cultivares de cana-de-açúcar, plantio (safra 2005/2006) e primeira soca (safra 2006/2007), Gurupi-TO.

\begin{tabular}{cccc}
\hline Cultivares & PROD Plantio & PROD Soca & MED Pl e So \\
\hline RB84-5210 & $88200,0 \mathrm{Ab}$ & $92222,0 \mathrm{Ab}$ & $90211,0 \mathrm{~b}$ \\
RB85-5113 & $69378,0 \mathrm{Ab}$ & $79555,0 \mathrm{Ab}$ & $74467,0 \mathrm{~b}$ \\
RB85-5453 & $56844,0 \mathrm{Ab}$ & $68000,0 \mathrm{Ab}$ & $62422,0 \mathrm{~b}$ \\
RB86-7515 & $77267,0 \mathrm{Ab}$ & $89111,0 \mathrm{Ab}$ & $83188,0 \mathrm{~b}$ \\
RB83-5486 & $58867,0 \mathrm{Ab}$ & $47111,0 \mathrm{Ab}$ & $52988,0 \mathrm{~b}$ \\
RB56-5230 & $134244,0 \mathrm{Aa}$ & $158222,0 \mathrm{Aa}$ & $146233,0 \mathrm{a}$ \\
RB85-5536 & $115311,0 \mathrm{Aa}$ & $110666,0 \mathrm{Aa}$ & $112988,0 \mathrm{a}$ \\
RB92-8064 & $77955,0 \mathrm{Ab}$ & $72666,0 \mathrm{Ab}$ & $75311,0 \mathrm{~b}$ \\
SP80-1842 & $79644,0 \mathrm{Ab}$ & $79111,0 \mathrm{Ab}$ & $79377,0 \mathrm{~b}$ \\
SP85-3877 & $84355,0 \mathrm{Ab}$ & $76888,0 \mathrm{Ab}$ & $80622,0 \mathrm{~b}$ \\
SP81-3250 & $98844,0 \mathrm{Aa}$ & $91888,0 \mathrm{Ab}$ & $95366,0 \mathrm{~b}$ \\
SP80-1816 & $136289,0 \mathrm{Aa}$ & $135222,0 \mathrm{Aa}$ & $135755,0 \mathrm{a}$ \\
SP87-365 & $64000,0 \mathrm{Ab}$ & $56333,0 \mathrm{Ab}$ & $60166,0 \mathrm{~b}$ \\
SP86-155 & $101067,0 \mathrm{Aa}$ & $125288,0 \mathrm{Aa}$ & $113177,0 \mathrm{a}$ \\
IAC86-2480 & $69800,0 \mathrm{Ab}$ & $104444,0 \mathrm{Aa}$ & $87122,0 \mathrm{~b}$ \\
\hline Med. Cult. & $87471,0 \mathrm{~A}$ & $92448,0 \mathrm{~A}$ & \\
\hline
\end{tabular}

Grupos de médias seguidas por uma mesma letra maiúscula na linha e minúscula na coluna, não diferem significativamente pelo teste de agrupamento de Scott and Knott a 5\% de significância.

\section{CONCLUSÕES}

As características, altura de plantas e número de plantas por hectare estão correlacionados diretamente com a produtividade.

Os cultivares, RB56-5230, SP80-1816, SP86-155 e RB85-5536 são os mais produtivos.

Os cultivares, SP80-1816 e RB85-5536 possuem os melhores resultados nos parâmetros quantitativos e qualitativos.

\section{RESUMO}

A cultura da cana-de-açúcar (Saccharum spp.) é destaque no cenário agrícola do Brasil, podendo ser atribuído à sua elevada capacidade de adaptação aos mais diversos ambientes. O objetivo deste trabalho foi avaliar o comportamento de quinze cultivares de cana-deaçúcar nas condições de clima e solo da região sul do Tocantins, em condições de cana de primeiro ano (2005/2006) e segundo ano (2006/2007). O delineamento experimental utilizado foi de blocos casualizados, com 15 tratamentos (cultivares) e três repetições. Os cultivares utilizados foram: RB84-5210, RB85- 
5113, RB85-5453, RB86-7515, RB83-5486, RB56-5230, RB85-5536, RB92-8064, SP801842, SP85-3877, SP81-3250, SP80-1816, SP87-365, SP86-155, IAC86-2480. As características avaliadas foram: altura total da cana (ATC, em m); sólidos solúveis (BRIX, em ${ }^{\circ}$ Brix); número de cana por hectare $(\mathrm{NCH}$, em $\mathrm{NC} / \mathrm{ha}$ ) e produtividade (PROD, em kg ha ${ }^{-1}$ ). Os dados experimentais foram submetidos à análise individual e, posteriormente, análise conjunta para algumas características, para comparação entre grupos de médias foi utilizado o teste de agrupamento Scott and Knott (1974) a 5\% de significância. As características ATC e NC/ha estão correlacionadas diretamente com a produtividade. Os cultivares RB56-5230, SP801816, SP86-155 e RB85-5536 foram os mais produtivos. Os cultivares SP80-1816 e RB855536 obtiveram os melhores resultados nos parâmetros quantitativos e qualitativos.

Palavras-chave: Saccharum spp., ambiente, produtividade, quantitativo e qualitativo

\section{REFERÊNCIAS}

Alfonsi, R. R.; Pedro, M. J.; Brunini, O.; Barbieri, V. (1987), Condições climática para a cana-de-açúcar. In: Cana-de-açúcar: cultivo e utilização, 1987. São Paulo: Fundação Cargill, 1, 856p.

Azevedo, H. J. (1981), Fisiologia da canade-açúcar. Araras: Programa Nacional de Melhoramento da Cana-de-açúcar, 1, 108p.

Barbosa, G, V, S.; Souza, A, J, R.; Rocha, A, M, C.; Ribeiro, G, A, G.; Ferreira, J, L, C.; Soares, L.; Cruz, M, M.; Silva, W, C, M. (2000), Novas variedades RB de canade-açúcar para Alagoas, Maceió: UFAL, Programa de Melhoramento Genético de Cana-de-Açúcar, (Boletim Técnico Programa de Melhoramento Genético de Cana-de-Açúcar, 1), 1, 16p.

Bernardes, M, S. (1987), Fotossíntese no dossel das plantas cultivadas. In: Ecofisiologia da produção agrícola. Piracicaba: POTAFOS, p.13-48.

Bernardes, M, S. e Câmara, G, M, S. (2001), Cultura da cana-de-açúcar, Piracicaba: ESALQ, Depto., de Produção Vegetal, 1. 20p.

Bezuidenhout, C. N.; O'Leary, G. J.; Singels, A.; Bajic, V. B. (2003), A process based model to simulate changes in tiller density and light interception of sugarcane crops. Agricultural Systems, 76, 589-599.

Casagrande, A. A. (1991), Tópicos de morfologia e fisiologia da cana-de-açúcar. Jaboticabal: FUNEP, 1, 157p.

Cesar, M, A, A.; Delgado, A, A.; Camargo, A, P, de.; Bissoli, B, M, A.; Silva, F, C. (1987), Capaciade de fosfatos naturais e artificiais em elevar o teor de fósforo no caldo de cana-deaçúcar (cana-planta), visando o processo industrial, STAB: Açúcar, Álcool e Subprodutos, 6, 32-38.

Cruz, C. D. (2001), Programa GENES Aplicativo computacional em genética e estatística. Viçosa: UFV, Imprensa Universitária. 542p.

Delgado, A. A. e César, M. A. A. (1977), Elementos de tecnologia e engenharia do açúcar de cana. Piracicaba: ESALQ, Depto., de Tecnologia Rural, 364p.

Dias, F, L, F. Relação entre a produtividade, clima, solos e variedades de cana-de-açúcar, na Região Noroeste do Estado de São Paulo, Piracicaba. Dissertação (Mestrado em Solos e Nutrição de Plantas) - Universidade de São Paulo, 1997.

\section{EMBRAPA (EMPRESA BRASILEIRA DE PESQUISA AGROPECUÁRIA).} (1999), Centro Nacional de Pesquisa de Solos. Sistema brasileiro de classificação de solos, Brasília.

Fernandes, A. C. (1985), Autorização da colheita da cana-de-açúcar. In: SEMANA DE FERMENTAÇÃ̃O ALCOÓLICA "JAIME ROCHA DE ALMEIDA", Anais. Piracicaba: Escola Superior de Agricultura "Luiz de Queiroz", Universidade de São Paulo, p.12-21.

James, N. I. (1971), Yeld components in ramdom and selected sugarcane populations. Crop Science, 11, 906-908.

Kang, M. S. and Miller, J. D. (1984), Genotype-environment interactions for cane and sugar yield and their implications in sugarcane breeding. Crop Science, 24, 435440. 
Machado, E. C.; Pereira, A. R.; Fahl, J. I.; Arruda, H. V.; Cione, J. (1982), Análise quantitativa de crescimento de quatro variedades de milho em três densidades de plantio, através de funções matemáticas ajustadas. Pesquisa Agropecuária Brasileira, 17, 1323-1329.

Magalhães, A. C. N. Ecofisiologia da canade-açúcar: aspecto do metabolismo do carbono na planta. (1987), In: Ecofisiologia da produção, 1987. Associação Brasileira para Pesquisa da Potassa e do Fosfato (POTAFOS). Piracicaba. p. 113-118.

Mariotti, J. A. (1971), Associations among yeld and quality components in sugarcane hybrid progênies. In: CONGRESS OF THE INTERNATIONAL SOCIETY OF SUGAR CANE TECNOLOGISTS. Proceedings. New Orleans: ISSCT. New Orleans. p. 177-184.

Matsuoka, S. (1996), Botânica e ecofisiologia da cana-de-açúcar. Apostila: Curso de Qualificação em Plantas Industriais - Cana-de-açúcar, São Paulo, 93p.

Scarpari, M. S. Modelos para a previsão da produtividade da cana-de-açúcar (Saccharum spp.) através de parâmetros climáticos. Dissertação (Mestrado em Agronomia) - Universidade de São Paulo, 2002.

Scott, A, J. and Knott, M. (1974), A cluster analysis method for grouping means in the analysis of variance. Biometrics, 30, 507512.

SEPLAN. (2003), Secretaria do Planejamento e Meio Ambiente do Tocantins. Atlas do Tocantins: Subsídios ao planejamento da gestão territorial. 3. Ed. Palmas-TO: SEPLAN, 49p.

Silva Junior L. D. (2001), Estágio de desenvolvimento exigências da cultura cana-de-açúcar. Viçosa: UFV, 1, 21p.

Shigaki, F. Variedade de cana-de-açúcar para alimentação bovina cultivadas sob condições de déficit hídrico. Dissertação
(Mestrado em Ciencia do solo) Universidade Federal Rural do Rio de Janeiro, 2003. 